\title{
4. Transforming Transparency into Trust: \\ An Analysis of the European Commission's E-Government and Citizen Trust
}

Jessica Roome, Hanna San Nicoló

\section{Introduction}

"Brussels is to spend $£ 600$ million over six years on feeding young people EU 'propaganda"' (The Sun, 31 October 2006)

"EU wirbt mit Softporno"1

(Bild Online, 3 July 2007)

"All male members of staff at the EU institutions can be partly reimbursed for the medical costs of six Viagra pills a month"

(Sondagsavisen, 25 August 2002)

"Skye's the limit for EU islands": EU changes the definition of an island" (The Guardian, 21 January 2003)

"EU vill lagra ditt flirt-sms"12

(Expressen, 27 September 2005)

These headlines from the 'Myths and Rumours debunked' section of the European Commission's (2011) website are just a few examples of the national press coverage of the European Union (EU). The European Commission has established this section because the "European media landscape [...] is still mainly national" with only a few media suppliers having a "truly European outreach" (DG Communication, 2010, p.4). In addition, the EU

11 EU advertises with softporn.

12 EU to store your flirtatious text messages. 
hardly has any of its own media to disseminate information (ibid.). Subsequently, it is mainly through national sources, often reporting misleading and wrong statements, that citizens form their perception of European institutions and actors.

Statistics suggest that the current climate of (dis)information is traceable in citizens' relationships with the European Union. According to the Eurobarometer of February 2011, only 43 percent of European citizens trust the European Union (2011a, p.43). What is also striking is that 66 percent think that they are badly informed about European political questions (Eurobarometer, 2011b, p.11) even though more than 80 percent recognize the importance of being informed about such issues (European Commission, 2007a, p.6). Is there a connection? By better informing citizens, could the EU foster a more positive stance towards the European institutions? In other words, does transparency lead to trust? Joseph Stiglitz (1999), former Senior Vice President of the World Bank, defines secrecy as antithetical to democracy and as a catalyst for mistrust between citizens and governments (p.2.).

Transparency and openness are given a new platform by the internet, allowing "government and citizens [to] more finely manage information" in an easier and cost effective way (ibid). In our age of modernity and technological progress, this form of online governance, known as 'e-government', has been heralded by some as having the possibility of "revolutionaliz[ing] the relationships between citizens and governments" (Hinnant and Welch, 2002, p.1).

In 2006, following the finding that " $65 \%$ of respondents to the Commission's public consultation on eGovernment [believe] that eDemocracy can help reduce Europe's democratic deficit", the European Commission launched its e-government action plan, trying to increase transparency via its website (European Commission, 2006, p.2). This objective was to be achieved by 2010, but it appears not to have been completely successful as indicated by the January 2011 Eurobarometer report, which reveals that only 44 percent of European citizens trust the European Commission (Eurobarometer, 2011a, p.41). This paper aims to address the European Commission's problem as to the ways of how transparency through e-government can and should be used to enhance citizen trust - as a factor of democratic legitimacy - in the European Commission.

Claiming that transparency through e-government in order to increase citizen trust in the European Commission cannot only involve the dissemination of information but rather has to be informed by other standards expected by citizens, this paper investigates factors which have to be present along with basic transparency so as to build up trust. Initially, three aspects of communication are proposed to play an important role in transforming transparency into trust. These are accessibility, interactivity and publicity. 
In addition, through the empirical research undertaken, it has arisen that the lack of individual interest in the European Commission is a substantial obstacle in the attempt to create trust through their e-government provision.

In order to answer the research question, a theoretical framework will firstly introduce the concepts used throughout this paper, and will explain the methods used to apply them. The following empirical analysis is based upon data collected through a complementary, multi-method research approach including a quantitative survey with 60 citizens and follow-up interviews with 30 respondents. In addition, an interview with $\mathrm{Mr}$. Taquet-Graziani from DG Communication provides insight into the Commission's strategy and views. The analysis is structured around three main groups of relationships. The first looks at the relationship between transparency satisfaction through e-government and trust in the European Commission. The second investigates the role of the three additional factors of accessibility, interaction and publicity in citizens' trust judgments. The last section examines the effect of interest on trust. Finally, an overall conclusion will be drawn, leading to a recommendation of how the European Commission should use its e-government in order to effectively foster citizen trust.

\section{Theoretical Framework}

\section{Conceptual Analysis}

As many scholars argue that "citizen perception of trust is a cognitive reflection of the information and data obtained by the public regarding governmental performance", it seems plausible to relate transparency to trust (Nye in Hinnant, Moon and Welch, 2004). If this is the case, then "we must be well on the high road towards an ever more trusting society" (BBC, 2004). This high road is based on "new technologies that are ideal for achieving transparency and openness" (ibid). For example, the internet constitutes a new platform for governments to be transparent through the provision of e-government. However, the internet also poses challenges to governments, as citizens' perceptions on transparency are now influenced by the increasing capacity the internet provides besides information dissemination (Hinnant, Moon and Welch, 2004). From existing literature accessibility, interaction and publicity can be identified as the most important factors influencing citizen satisfaction with transparency through e-government. The following section will discuss these concepts separately, showing how they are operationalized in the empirical research. 


\section{Trust}

Trust exists when "one party has confidence in another's reliability and integrity" (Sweeney, 104, 2007). Focusing on 'political trust' two analytical categorizations can be made (Blind, 2006, p.5). Firstly, the differentiation focuses on towards whom the trust is directed. "Macro-level or organizational trust" describes citizen trust in a political system and its organizations. "Micro-level or individual trust" refers to trust in individual political actors (p.4). Secondly, the motivations behind trust judgments can be differentiated. They can be based upon either rational calculations involving the evaluation of the congruence of political interests, "rational trust" (ibid.), or on an "assessment of the moral values and attributes associated with a certain government, political institution and/or individual political leaders", which is the case in "psychological trust" (p.5).

Regarding the relationship between transparency and trust, Welch, Hinnant and Rae Moon (2004) discuss the ways in which information plays a role in trust judgments. Fiduciary trust exists where there is a principal-agent relationship between two actors, with the principal holding more information than the agent, creating an asymmetric information relationship. This means that the release or discovery of information by the agent about the principal increases the trust. Mutual trust is developed through interpersonal interaction, and thus cannot exist between an institution and an individual. Social trust is increased by exchange of information and social interaction (p.377). Therefore, an increase in transparency through more dissemination of information by a political institution could provoke an increase in fiduciary trust, as the information asymmetry would be decreased. In order to promote social trust, the institution would have to engage in an exchange of information with citizens. Citizen trust is measured in two ways. Firstly, respondents were directly asked to what extent they trust the European Commission. Secondly, as with all of the following variables, it is measured by calculating the combined average of a number of elements:

Citizen trust in the European Commission $=f$ (confidence in reliability, confidence in integrity, perception of congruence of interest, perception of coordinated action)

\section{Transparency and E-Government}

Transparency is defined as the "availability of information to the general public and clarity about government rules, regulations and decisions" (Asian Development Bank in Hood, 2007, p.4). According to Hüller (2007), there are four preconditions for transparency: the production of information, a supply of that information, no costs to receive the information as well as a reception of the supply of information (p.566). Thus, transparency is the 
dissemination of information about the actions of a government or political institution to its subjects, which will be the understanding framing this research.

E-government is a useful tool to achieve transparency through the dissemination of information, providing a "layman's basic map of the organization as depicted in the information on the site [and] reveal[ing] the depths of access it allows [and] the depths of knowledge about processes it is willing to reveal" (Cyberspace Policy Research Group in Hinnant and Welch, 2002, p.2). E-government is the use by all levels of government of new technological means, especially the internet, to provide services, information and the possibility to participate in the democracy process. E-government has the potential to provide a basis for "transparency downwards", where the agent (the citizens) can observe what the principal (the political institution) is doing (Heald, 2007, pp.27-28).

When discussing the dissemination of information through e-government, 'transparency satisfaction' will be assessed (Hinnant, Jae Moon and Welch, 2004, pp. 381382) and not transparency as a quantity in itself.

Transparency satisfaction $=f$ (perception of reliability, perception of quality, demand of more information)

Following from these conceptions of trust and transparency through e-government, a first hypothesis can be drawn:

$\mathrm{H} 1$ : There is a positive relationship between transparency satisfaction through the European Commission's e-government and trust in the institution.

\section{Accessibility, Interaction and Publicity}

Accessibility is the degree to which people have access to e-government. As Hinnant and Welch (2002) demonstrate, e-government can exclude social groups who lack certain economic (e.g. PC and internet) and educational means (e.g. technological skills and background knowledge). In addition, certain characteristics of a website need to be satisfactory in order for the information to become accessible to users. Firstly, the information has to be understandable, both in terms of not being too technical, and being available in the preferred language of the user (Cheung and Lee, 2005). Secondly, the website should be well structured, so that it is easy to navigate (ibid.).

Accessibility satisfaction $=f$ (structural accessibility, intelligibility, skills, means, knowledge) 
A differentiation has to be made between one-way interactivity and two-way interactivity (Welch and Hinnant, 2002, p.1). Whereas one-way interactivity can be understood as top-down dissemination of information, two-way interaction entails the ability of governments to involve its citizens in public policies. It includes the possibility for citizens to give immediate feedback, as well as the ability or willingness of the government to be responsive to its citizens (p.4). Optimally, interaction should give users the feeling that they can hold an institution accountable, and could exert influence. This paper uses the concept of two-way interactivity.

Interactivity satisfaction $=f$ (possibility of feedback, two-way communication, influence, acknowledgement by European Commission, accountability)

Publicity is attained when citizens are aware of information available thanks to transparency. Hüller (2007, p.565) emphasizes three important aspects and consequences of publicity. Firstly, publicity implies that relevant documents are published and that policy-making is open to everybody. Secondly, publicity is necessary "to give each citizen an effective opportunity to follow these processes and documents in a meaningful way" (Council in Hüller, 2007, p.565). Thirdly, publicity expects citizens to use transparency. In this context, publicity "requires that almost everybody knows enough about essential political issues and choices" (ibid.).

Publicity satisfaction $=f$ (perceived levels of publicity, demands for more publicity, use of alternative sources)

It is proposed that these elements are expected by citizens, due to their knowledge of the potential of the internet. Thus, in addition to transparency satisfaction, they influence overall perceptions of e-government, and in turn, citizen trust. Therefore, a second hypothesis is introduced:

$\mathrm{H} 2$ : The positive relationship between transparency satisfaction through the European Commission's e-government and trust in the institution is strengthened when there is also satisfaction with accessibility, interaction and publicity. 


\section{Data collection}

The multi-method approach, with both qualitative and quantitative data collection, was based around a sample group of students from Maastricht University. Due to the international character of the University, it is assumed that students potentially have a higher level awareness and interest on the European Union than in other universities. This is proposed to enrich the value of the research, as it increases the possibility that respondents have informed and considered perceptions on the issues dealt with. It is assumed that students have a high level of experience with internet and the services provided electronically, which increases the likelihood that they have knowledge of the possibilities of e-government provision.

Respondents were selected using the 'snowball method' where an original core group of 10 respondents were asked to each recommend another student, who then recommended another until the sample number of 60 persons was reached. Of the questionnaire respondents, every second was interviewed. The resulting sample for both the questionnaire and the interview contains an above average proportion of European Studies and European Law students ('EU-Studies'), compared to the 'other faculties'. This fulfills the intention to analyze the opinions of well-informed citizens, but it limits the ability to use the results to generalize about both students' and the European population's perceptions. During the questionnaire, respondents were given five minutes to navigate around the European Commission's website. Their perception on the website were then measured, using Likert scales from 1-5, with one being the most negative response, 5 the most positive, and 3 neutral. The interview was conducted in a semi-structured manner. The data retrieved through the questionnaires was analyzed using SPSS. The interviews were coded according to the central concepts identified, and sorted into positive, negative and neutral opinions. "As causality cannot generally be established from data such as ours, the interviews will be used to enhance te analysis of the relationships between the variables in this way". In addition to the survey and interviews with students, an interview with Mr. Taquet-Graziani, Information and Communication Officer for the Commission's, President's \& Commissioners' Websites, DG Communication, was conducted in Brussels, May 19, 2011. 


\section{The relationship between transparency satisfaction through e-government and citizen trust}

In order to analyze the relationship between transparency satisfaction and trust, theorized in hypothesis 1, the two variables will first be discussed separately. To measure respondents' transparency satisfaction through the European Commission's e-government they were asked to what extent they thought the website was a useful tool to achieve transparency. On a Likert scale from 1-5, the mean average response was 3.78, which shows that the website was neutral to fairly well received by students as a tool for increasing transparency. This can also be seen in the high frequency of positive responses and the mode response of 4 (graph 1).

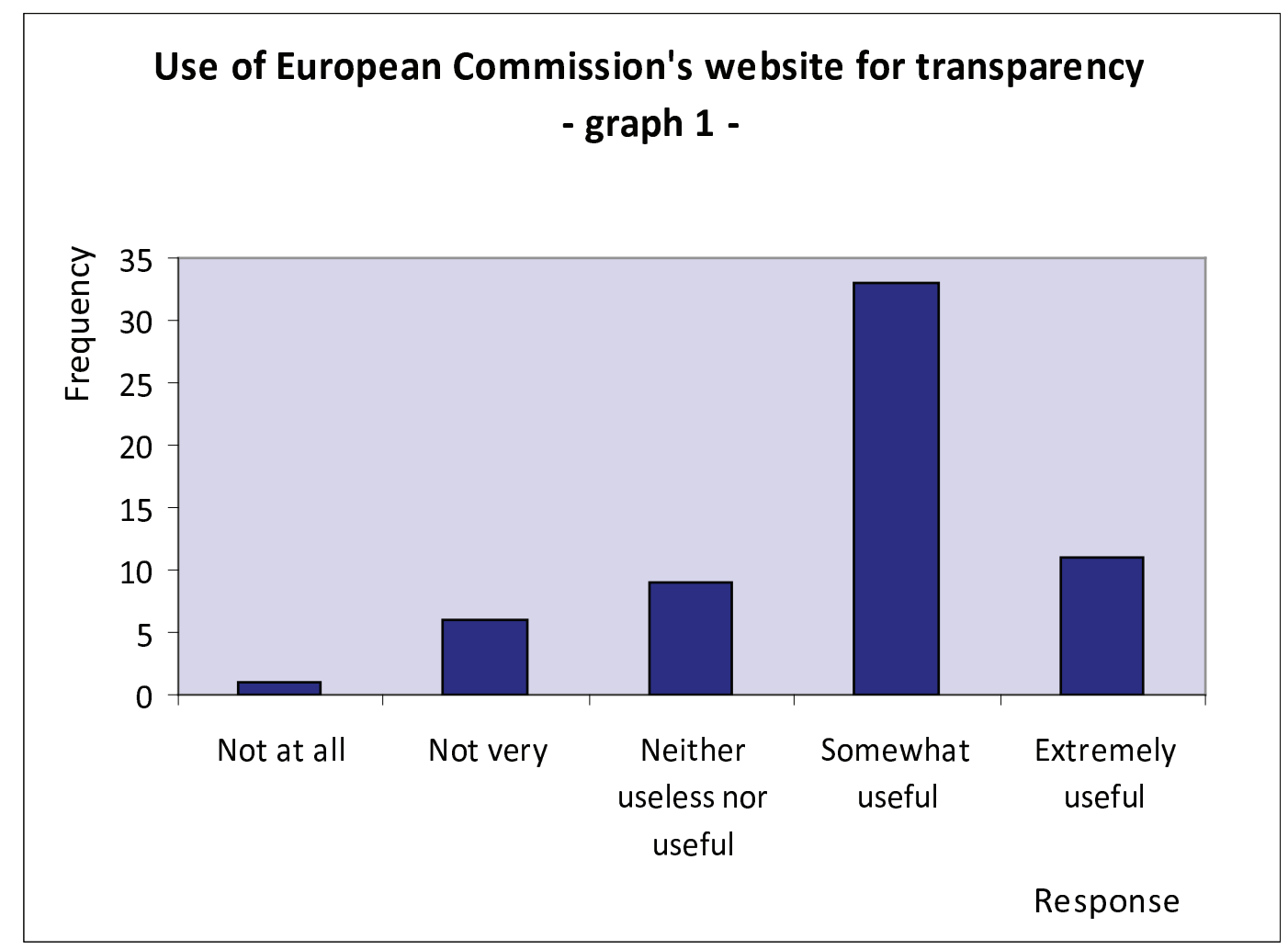

When respondents were asked how much they trust the European Commission the mean was 3.32. As shown in graph 2, the mode of 3 and the lack of extreme responses also reflect the neutral feeling of trust among respondents. 


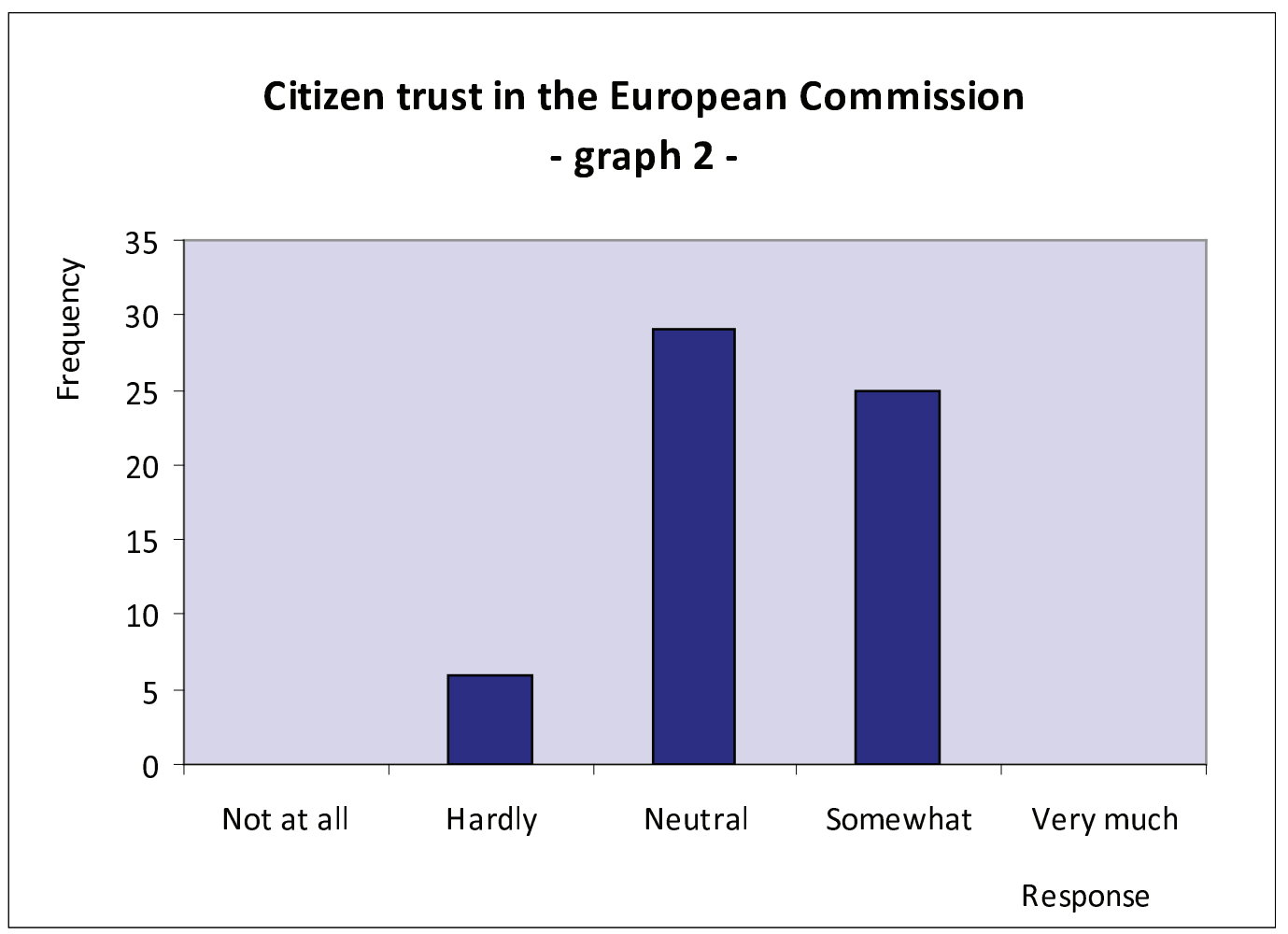

As proposed in hypothesis 1 , the outcome of the survey testifies that there is a relationship between trust and transparency satisfaction. There is a significant positive, but weak, relationship between trust and transparency satisfaction (Pearson correlation coefficient $[r]=0.277$, significance $[p]=0.032)$. Looking at trust and the individual elements of transparency satisfaction, the correlation to satisfaction with the reliability of information on the website is $0.332(p=0.010)$. It is interesting to see that reliability of information is particularly important for citizens' trust. The relation between trust and satisfaction with the quality of information, $0.277(p=0.032)$, is identical to the relation between trust and overall transparency satisfaction. This is probably the case because the correlation between overall transparency satisfaction and satisfaction with the quality of information is strongly significant. Thus, the reliability and quality of information are the aspects of transparency satisfaction which are mostly related to citizens' trust in the European Commission. The multiple regression of transparency satisfaction with citizen trust results in an $\mathrm{R}^{2}$ value of 0.077 , with a significance level of 0.00 . This means that 7.7 percent variance of citizens' trust is explained by the model, i.e. by variance in transparency satisfaction. Overall, these quantitative results show that there is a positive relationship between transparency satisfaction through the European Commission's e-government and trust in the institution. In the interviews most respondents argued that transparency is important for their trust, 
as it gives an insight into the documents and events of the European Commission. This decreases the feeling that anything could be hidden. One student expressed a wish for more transparency, saying that "complete transparency", with webcams filming the work and access to all papers, would increase her personal trust. On the other hand, there were some students who stated that transparency was not important for their trust. One person claimed that "transparency and trust are interlinked, but [...] it is not necessary that if there is more transparency there is more trust" since understanding the processes might lead to less trust. Despite these few exceptions, the outcomes were in favor of transparency. The first reaction to the question if transparency increases personal trust was often "of course" as if the two concepts were fundamentally and naturally related. Mr. Taquet-Graziani also strongly related the two concepts, and argued that transparency via the European Commission's website is "at least one of the main tools available" to achieve trust.

In the interviews, respondents were asked whether and to what extent they see the website as a means to increase their trust. The respondents were roughly split. Those arguing that the website had a positive effect on their personal perception of and trust in the European Commission claimed that the website is clear and makes it possible to find all information people need. If the information needed cannot be found, people appreciate the possibility to request it. Moreover, they said that it "looks structured" which makes the European Commission appear trustworthy and reliable. The pictures of the heads of the Commission were said to trigger a feeling of closeness as they allow identifying the individual actors, giving the abstract institution a face. Others mentioned the interaction settings as increasing their personal trust. It was pointed out that the website is "one step to increase trust", as it shows the European Commission's willingness to increase transparency and to hear other people's opinions, which means they are open to criticism

The website did not change some students' trust as they argued that 'just a website does not mean anything" and that the overall relationship between EU and its citizens needs to be changed. One student in this regard stressed "some marketing people could have done [the website]" and that "trust is about what they do, rather than what they publish". Moreover, it was argued that "just because a government has a face, it does not mean it will talk back". Students recommended that the European Commission should more focus on other channels, such as Facebook, to communicate with its citizens, as many of them would not go for the website first.

There is a positive correlation between transparency through e-government and citizen trust, with transparency satisfaction explaining 7.7 percent of change in trust. Furthermore, from the interviews it can be concluded that this is a causal relationship, so an increase in transparency satisfaction through e-government increases triggers an 
increase in personal trust. This was particularly the case for those who consider themselves to be uninformed. They originally gave neutral responses, as they did not feel they had a base on which to found their trust. Thus, the website provided this foundation for trust. Many who had a positive trust judgment identified transparency as a main factor already informing their trust.

There were suggestions that the relationship between transparency through e-government and trust could be strengthened. Frequently respondents were skeptical about the quality of transparency a website could provide because it could manipulated and just be a façade. Because trust runs deeper than a website, the European Commission needs to change its relationship with citizens significantly. Despite these partly critical responses, overall, the first hypothesis that there is a positive relationship between transparency satisfaction through e-government and citizen trust in the European Commission can be validated through the empirical research.

When discussing the transparency provided through the website and their satisfaction with it, respondents often included other factors in their judgment, which have been measured separately in this research. For them, these other characteristics are considered to be part of transparency, rather than separate. For example, they mentioned the accessibility of the website (language options, understandability of information and ease of navigation) and the possibilities to give feedback and address questions to the European Commission. This indicates that simple information provision is not the only aspect of a website influencing citizen trust. Therefore, the results from the analysis of hypothesis 1 already give a strong indication that the second hypothesis holds some truth, which will be elaborated upon in the following section.

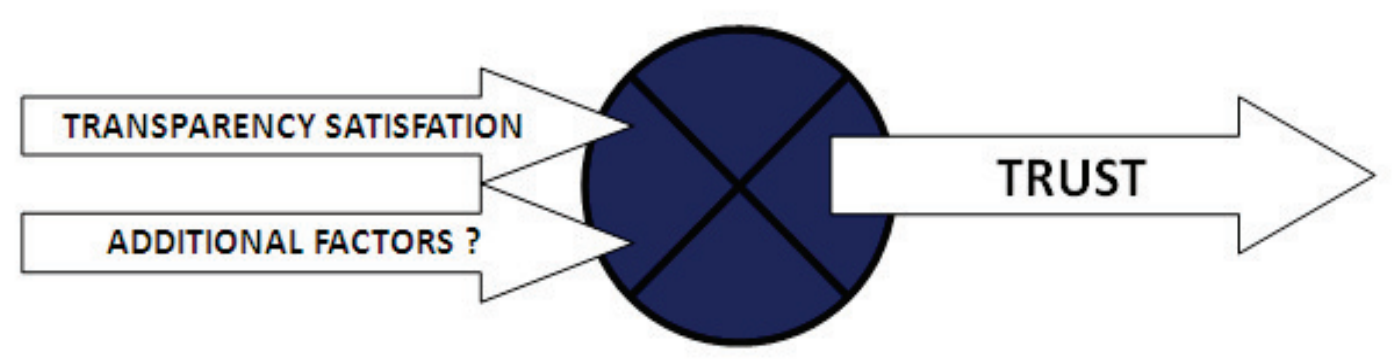




\section{Accessibility satisfaction}

The mean value of accessibility satisfaction is very high, at 4.08 . Several respondents thought that the website is well structured and easy to navigate. However, many highlighted that a problem faced by first-time visitors with little or no background knowledge is that you have to "click on 5000 things" in order to get to the information you want. This leads to the problem that their message is not being transmitted clearly and results in an "information overload." As one student argued, "for someone who's not really into the European Commission, I don't know what to look for, I just what to have some general information". The point that the website is hard to navigate if you are not "into the topic" was raised frequently, and respondents thought that the website should be more straightforward, that it is missing "eye catchers" and that "sometimes less is more".

The respondents viewed the website in English, which was no obstacle to their use, as all but one study in English. Nonetheless, many mentioned the importance of the website being available in all EU languages. This was also a main point made by Mr. TaquetGraziani, who remarked that it is "a key constraint and we get criticized all the time", as currently much of the website is not available in all EU languages. The Commission is an administration of 20,000 people among which 1500-2000 have the task to communicate to half a million people in 23 languages in 27 countries. According to an assessment by the European Commission they would need 9000 extra translators to translate the whole website into every EU language. Thus, Mr. Taquet-Graziani argues that "you can just not handle it" considering the large scale of the task and states that the European Commission must cooperate with other partners.

Overall, it appears that respondents are relatively satisfied with the accessibility of the website. However, there are some issues surrounding the easiness of use of the website for people who do not already have an overview of the work of the European Commission. Moreover, as emphasized by Mr. Taquet-Graziani, one of the main obstacles to full accessibility is the remaining language barrier

\section{Interaction satisfaction}

Overall interaction satisfaction is fairly low, with a mean value of only 2.68 . Interestingly, there is a large difference between the satisfaction with the provision (immediate feedback and discussion possibilities), and the feeling that using the provision could be useful (exerting influence and holding accountable). The mean value of satisfaction with immediate feedback possibilities is 3.27 and of satisfaction with possibilities of discussion is 3.00. These values are quite a lot higher than the feeling of exerting influence on the EC by using the website (2.12) and feeling of holding the EC accountable (2.32). These 
differences indicate that whilst respondents are neither satisfied nor dissatisfied with the provisions for interaction via the website, their dissatisfaction mainly comes from the feeling that using these tools would not make any difference, as they do not think they could hold the Commission accountable or influence their work in this way.

These different opinions on interaction via the website in theory and in practice were also reflected in the interviews. One respondent was positively surprised by the possibilities to contact and interact with the Commission as she had expected a "very conservative, purely informative website". Several saw these interaction possibilities as demonstrating the European Commission's desire to make citizens feel that they could have more influence and that it tries to integrate public opinion. Two respondents said that even if they could not be sure they could exert influence or hold the Commission accountable, it was important to have the possibility through the website to at least try to. Other consequences of the interaction functions which were mentioned as positive were the fact that blogs enabled other perspectives to be voiced on the website, that they "give the Commissioners a face" and that the website was seen as being a good way to address specific questions. One respondent was very satisfied with a response she received to a question she had posed to the health department, as she thought they had tried very hard to help.

Conversely, a large number of people raised concern over how responses to questions and feedback are managed, for example, whether the Commission just responds to "nice questions". There was skepticism over the amount of time it would take to actually go through all the feedback, and how much is actually processed at a "high level". This view that feedback or questions just go to "somebody behind a desk", is related to the high levels of doubt that citizens could have any impact in this way. Many did not think it would be possible to exert any influence on the policy-making process, as "a single post wouldn't be powerful enough to influence the opinion of a Commissioner". Similar opinions were numerous about holding the Commission accountable. One said that even the new possibility of citizen petitions seem "impossible" to achieve, and although the Commission is doing things to make people feel involved, it feels almost useless, and still needs to be processed. National government and lobbyists were mentioned as a better way of approaching the European Commission, as "one person in the European Union" might not have enough standing to do so.

Mr. Taquet-Graziani countered these doubts about the effectiveness of using the interaction tools by stressing that there are strict rules according to which every question addressed to a Commissioner has to be answered within two weeks. In addition, "people do not know it, but the best way to get a reply is sending a question to Barroso!" Although students complained that they do not feel that they could exert influence by interacting 
with the European Commission, Mr. Taquet-Graziani explained that the European Commission undertakes large-scale consultation with industries, NGOs and civil society before introducing a legislative proposal. However, he recognizes that it is a problem that this is not shown enough on the website and, thus, "[it] should be more advertised by the European Commission".

Another source of concern for many respondents was the fact that they do not think people are interested enough to take advantage of the interaction possibilities. For example, regarding discussions on blogs, one said that people can only talk about the things they know, and the problem is that many do not know much about the Commission. Thus, many people were surprised that these interaction tools even exist.

\section{Publicity satisfaction}

Publicity satisfaction is quite low with a mean response of 2.38 , indicating that people think there should be more information about the website. In the interviews, some did express the feeling that it is individual responsibility to inform oneself, rather than an obligation of the European Commission. In addition, it was mentioned that Member States and national media should advertise more the website and the tools it provides. However, a large number of respondents stated that they thought the European Commission should do more to approach citizens, especially as the website does not currently reach its target group. This opinion was echoed by Mr. Taquet-Graziani. Several respondents said promotion was important to make people aware that they have the possibilities to "have a say" through the website and that there is a lot of useful information provided, for example about available study grants. Many indicated that social networking sites would be a useful way to advertise the website, to try to get a broader community of users. Another crucial problem highlighted was that as people are not very interested in the Commission and are not in contact with it in daily life, they do not actively seek to engage with the institution through the website, but rather take in information through more passive media sources, such as the television. Thus, to "try to include the people", the European Commission should actively inform people through broader education initiatives, as "people need to get more interested in the European Union itself" since that is "the base to make the website more used by citizens".

In conclusion, citizen satisfaction with the European Commission's publicity of its website was rather low. To some extent people would like to be better informed, but this is slightly lower than the feeling that the Commission has a certain degree of responsibility to inform citizens. As indicated by many in the interviews, there is a feeling that a priority would first be to increase general interest and knowledge of the European 
Commission and its role, so that promotion for the website would take place in a more fertile environment.

\section{Relationship between the additional factors and transparency satisfaction}

Transparency satisfaction tends to be fairly strongly related to satisfaction with the other factors. The correlation coefficient of accessibility satisfaction with transparency satisfaction is $0.532(p=0.00)$. This confirms what was observed in the interviews that when people discussed transparency provided through the website, they considered accessibility to be part of integral to transparent provision. For example, they identify understandability of language and ease of navigation as being a factor of the Commission being transparent through its website. Thus, the two factors are very interlinked and it could be interpreted that accessibility satisfaction is a factor of transparency satisfaction, rather than a separate characteristic. Moreover, there is also a reasonably strong correlation between transparency satisfaction and publicity dissatisfaction $(r=-0.313, p=0.015)$. Once again, this suggests that citizens see promotion of the website as important to be able to see the provision as transparent.

However, surprisingly, interaction satisfaction has a very low positive correlation with transparency satisfaction $(r=0.142, p=0.278)$. This result could be due to the fact that even if respondents are satisfied with the tools provided for interaction, they still have a very low opinion of the value this could have. By breaking down these two aspects of interaction satisfaction and then correlating with transparency satisfaction this interpretation becomes apparent. The correlation between interaction provision satisfaction and transparency satisfaction is $0.220(p=0.92)$, which is significantly higher than with satisfaction with the value of interaction at only $0.026(p=0.841)$. Therefore, provision of interaction tools is positively correlated with transparency satisfaction, but there is almost no relationship with satisfaction with the value of this provision.

\section{Relationship between the additional factors and trust}

There is a slight positive correlation between citizen trust and the additional factors of satisfaction with accessibility, interaction and publicity, with correlation coefficients of 0.246, $(p=0.58), 0.191(p=0.145)$ and 0.131 ( $p=0.317)$ respectively. As discussed earlier, the $R^{2}$ of the regression of transparency satisfaction and trust is 0.077 , which means that the model explains 7.7 percent of the variance in citizen trust $(p=0.00)$. When the three additional factors are added to the regression function, the model explains 11.2 percent of variation in trust. However, the significance falls to 0.156. Despite the increase in the $\mathrm{R}^{2}$ value 
by 0.035 (explaining 3.5 percent more variation), this significance level shows that the four factors are overlapping in the variation that they explain. Along with indications from the interviews, it can be concluded that, to some extent, transparency, accessibility, interaction and publicity satisfaction are measures of the same citizen perception. Probably, citizens see the three additional factors as important components of transparency. When the four factors are combined accordingly, the correlation with trust is fairly strong at 0.309 , with the high significance level of 0.016 .

Therefore, the second hypothesis, that the positive relationship between transparency satisfaction through e-government and trust in the institution is strengthened when there is also satisfaction with accessibility, interaction and publicity, is correct to some extent. However, it appears that the original conception of transparency as pure information dissemination, proposed by this paper, is too narrow. Citizens consider transparency to not only include information provision, but also these other characteristics. The analysis of the first hypothesis revealed only a weak relationship between transparency satisfaction and citizen trust, since transparency satisfaction was measured purely as information dissemination, excluding the other three factors. Thus, the research has shown that:

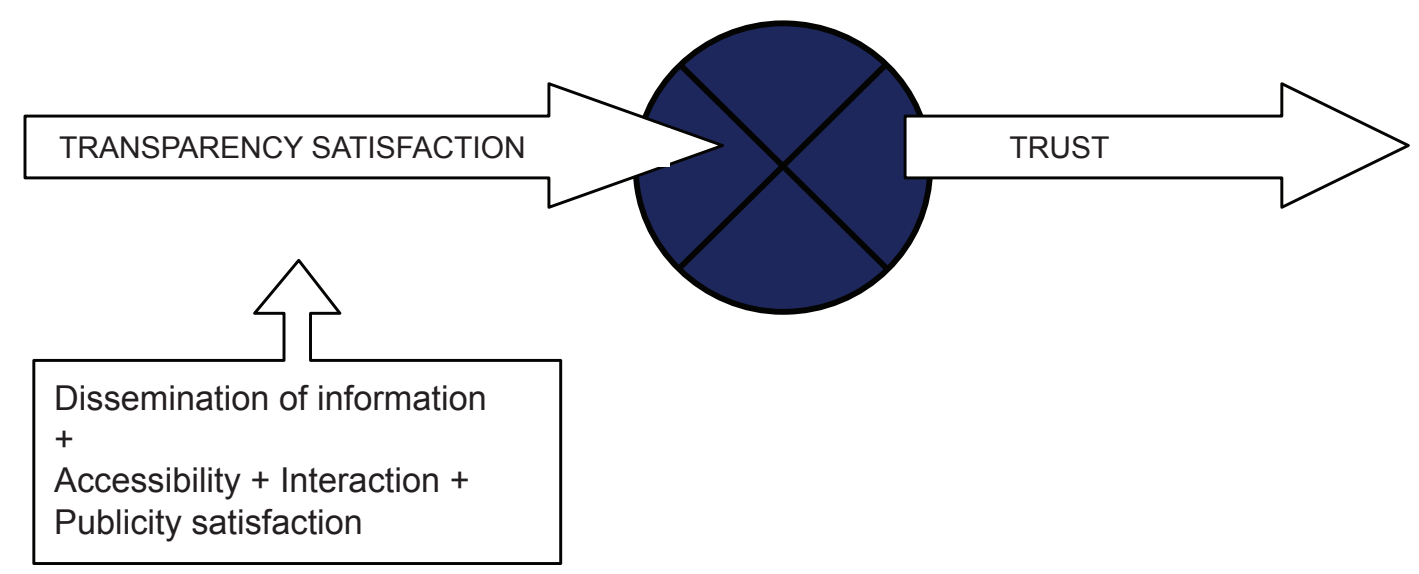

Besides this re-imagination of transparency satisfaction through e-government, a recurring element raised by interviewees when discussing the website of the European Commission and their satisfaction with it was the issue of general citizen interest in the institution. Therefore, an additional hypothesis is proposed regarding the relationship between citizen trust and transparency satisfaction with the website. It is proposed that:

$\mathrm{H}_{3}$ : In order for the now re-defined transparency through e-government to effectively increase trust, citizens must also be interested in the institution. 
The interest level amongst respondents is very low, with a mean value of only 3.08. As illustrated by graph 3, the majority of respondents were 'neutral' about their interest in the European Commission (48.3 percent).

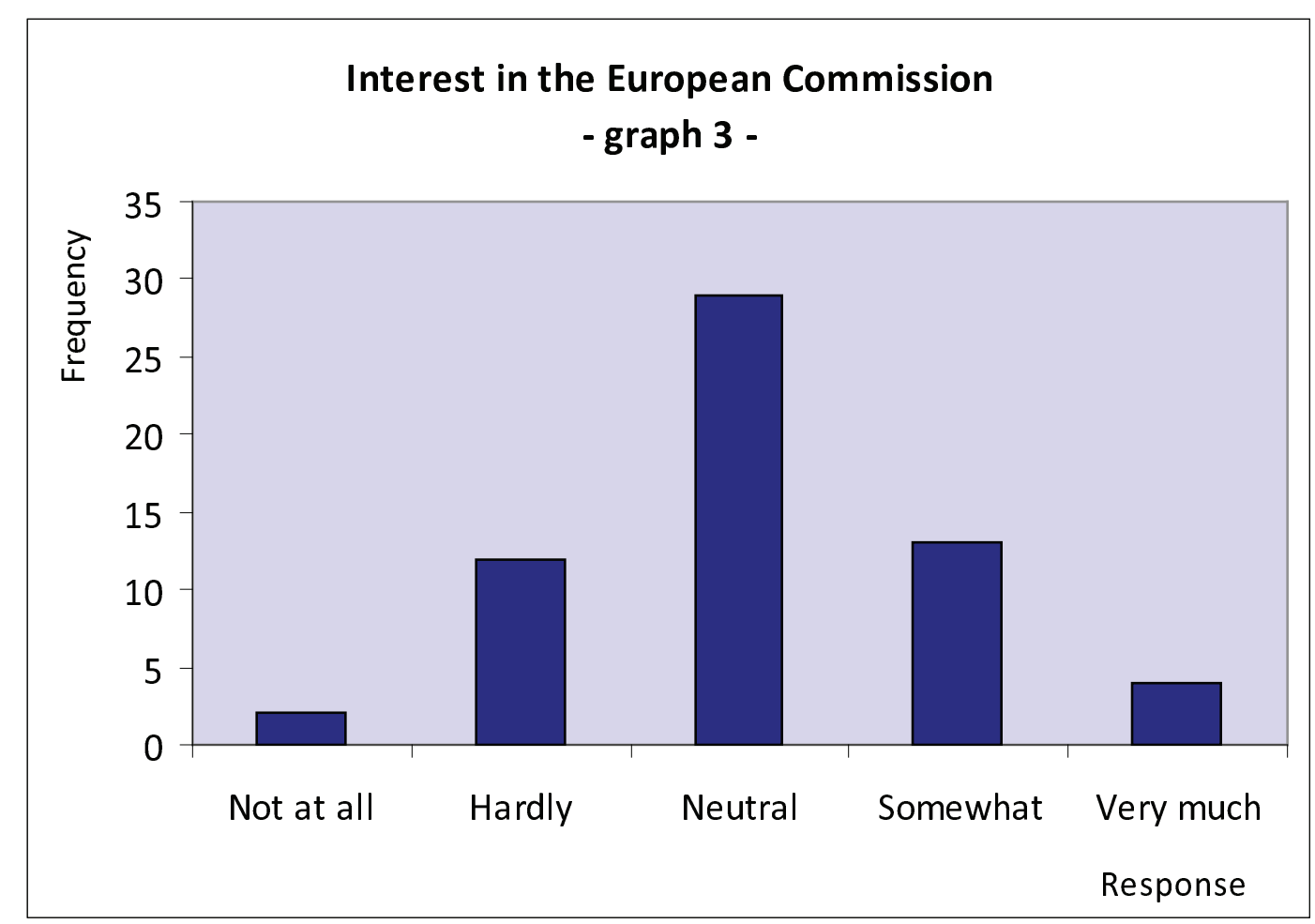

The results indicate that respondents are not actively disinterested, but rather could better be described as being disengaged from the institutions, and possibly many had not previously considered their opinion about the European Commission. This was reflected in the responses given in the interviews, where the majority argued that the EU seems very abstract and distant, "all the way over there in Brussels".

Mr. Taquet-Graziani recognizes that, whilst the European Commission provides a "huge amount of information [on its website ...], the problem is that this information is [only] available for people who will go there and look for it". A large part of society, which is not interested in the European Commission, would not go to its website. He criticizes that the European Commission is too bureaucratic and argues it should behave more as a political institution, and should "accept political exposure, accept that [it] will have critics but [it] will also have supporters". This could be a possible solution to the disengagement and disinterest in the European Commission. Thus, according to Mr. Taquet-Graziani, the European Commission should promote political debate. 
Elaborating on this disengagement among citizens, it has been found that there is a fairly high positive correlation between interest and trust in the European Commission, which is $0.328(p=0.011)$. When interest is added to all other satisfaction measures in the regression calculation discussed earlier, the model explains 23.9 percent of the variance in citizen trust, compared to 11.2 percent without interest. In addition, interest is a very significant element $(p=0.004)$. This demonstrates the importance that interest holds in the relationship between transparency through e-government and citizen trust. From discussing the issues with respondents during the interviews, it was apparent that they thought that to take advantage of transparency through e-government, a certain degree of interest was first necessary. Subsequently, in order for transparency through the website to effectively increase trust, citizens must also be interested in the institution, as hypothesized in $\mathrm{H}_{3}$.

The new model of the transformation of transparency into trust can, therefore, be visualized in the following way:

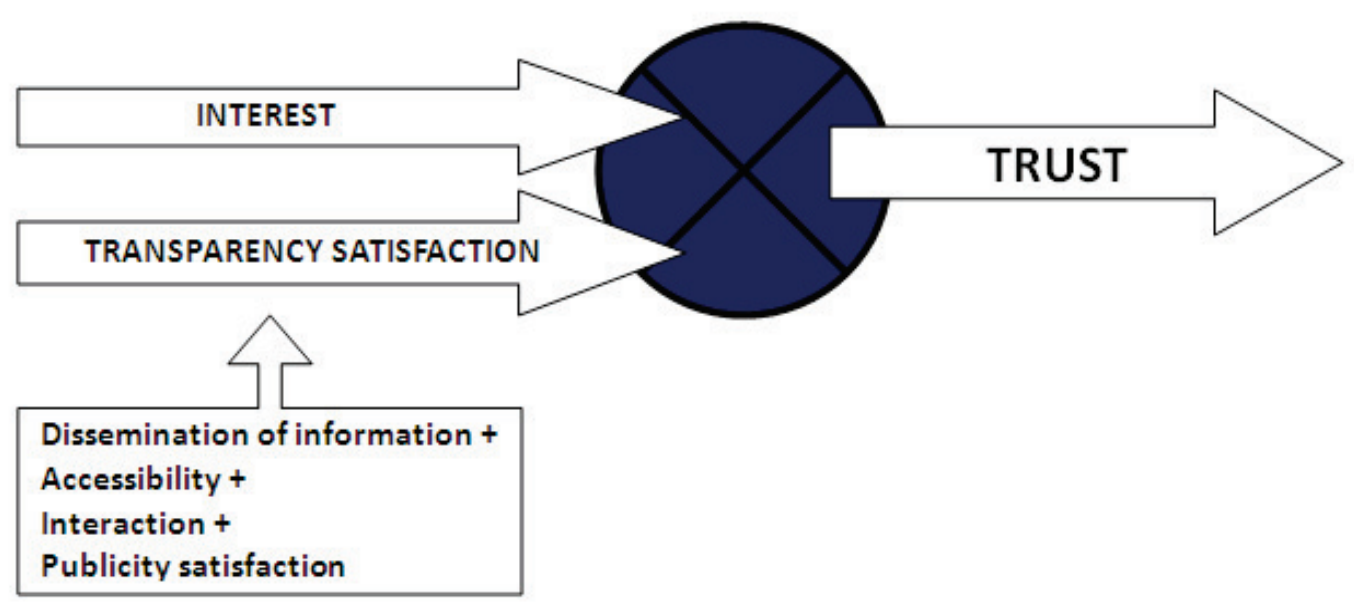




\section{Conclusion}

As was disussed at the beginning of this paper, there is currently a worrying trend towards 'dis- and misinformation' in and about the European Union, possibly due to the hegemony of the national press in the European media landscape. At the same time, there are strong indications that the public is wary of the Union: "for the first time in history [...] distrust in the European Union outweigh[s] trust" (Eurobarometer, 2011a, p.43). Unsurprisingly, this lack of trust was also echoed in citizen opinion on the most supranational institution of the European Union, the European Commission. In this context, attention was drawn to the possible connection between such an uninformed citizenry and their attitude towards the "distant" and "abstract" institution. The paper claims that transparency through e-government could provide a solution to these problems, not on its own in the form of pure information dissemination, but combined with improved accessibility, meaningful interaction and effective promotion. Furthermore, it has been found that transparency through e-government should be re-defined to include all of these elements. However, the fundamental issue is the lack of interest in the institution, a problem which must be solved first in order to create a "fertile ground" for e-government and its different dimensions to be an effective stimulator of citizen trust in the European Commission. Therefore, the overall finding of this paper is that, with the presence of citizen interest in the European Commission, transparency through e-government can foster citizen trust in the institution.

From the interview with Mr. Taquet-Graziani it is clear that the Commission is aware of some of its shortcomings and recognizes its responsibility to tackle these. Mr. TaquetGraziani emphasized that the European Commission currently acts as a bureaucratic rather than a political institution and proposed that being more involved in political, sometimes controversial, issues would promote public debate, sparking interest and attracting people to make use of the re-defined transparency provided through e-government. Further research into the relationship between transparency through e-government and democratic legitimacy could provide insight into the overall importance of a virtual dimension for social relations between political institutions and their citizens. Such an analysis could complete the formula proposed in this paper for using transparency to solve the EU's democratic deficit in the technical age. 


\section{Bibliography}

BBC. (2004). Reith Lectures 2002: Trust and Transparency. Retrieved June 3, 2011 from http://www.bbc.co.uk/radio4/reith2002/lecture4.shtml

Blind, P. K. (2006). Building Trust in Government in the Twenty-First Century: Review of Literature and Emerging Issues. UNDESA: Vienna, Austria.

Brannen, J. (2004). Working Qualitatively and Quantitatively in ed. Seale, C. et al. Qualitative Research Practice. pp.314-327. London: SAGE

Cheung, C. and Lee, M. (2005). The Asymmetric Effect of Website Attribute Performance on Satisfaction: An Empirical Study. Proceedings of the 38th Hawaii International Conference on System Sciences

DG Communication. (2010). Communicating Europe. The Contribution of DG Communication. Internal Publication: Brussels

Eurobarometer. (2010). Special Eurobarometer 335: E-Communications Household Survey. Brussels

Eurobarometer. (2011a). Eurobarometer 74: Public Opinion in the European Union. Brussels

Eurobarometer. (2011b). Eurobarometer 74: Information on European Political Matters.Brussels European Commission. (2010). The European e-Government Action Plan 2011-2015.

Harnessing ICT to promote smart, sustainable \& innovative government. COM(2010) 743

European Commission. (2006). eGovernment Action Plan: Accelerating eGovernment in Europe for the Benefit of All. Communication from the Commission to the Council, the European Parliament, the European Economic and Social Committee and the Committee of the Regions. $\operatorname{COM}(2006) 173$ final

European Commission. (2007a). Communicating Europe in Partnership. Communication from the Commission to the European Parliament, the Council, the European Economic and Social Committee and the Committee of the Regions. COM(2007) 568 final

European Commission. (2007b). Communicating about Europe via the Internet. Engaging the citizens. Communication to the Commission. SEC (2007) 1742

European Commission (2011). Myths and Rumours debunked. Retrieved June 5, 2011 from http://ec.europa.eu/dgs/communication/take_part/myths_en.htm

Europa (a). (n.d.) Glossary: Transparency (access to documents). Retrieved June 2, 2011 from http://europa.eu/legislation_summaries/glossary/transparency_en.htm

Fisher, J., van Heerde, J. \& Tucker, A. (2010). Does One Trust Judegement Fit All? Linking

Theory and Empirics. Political Studies Association. Vol. 12 pp.161-188

Giddens, A. (1990). The Consequences of Modernity. Oxford: Polity Press 
Harvey, D. (1989). The Condition of Post-Modernity: An Enquirey into the Origins of Cultural Change. Oxford: Blackwell

Heald, D. (2007). Varieties of Transparency in eds. Hood, C. \& Heald, D. Transparency: The Key to Better Governance? Oxford University Press.

Hood, C. (2007). Varieties of Transparency in eds. Hood, C. \& Heald, D. Transparency: The Key to Better Governance? Oxford University Press.

Hinnant, C., Jae Moon M. \& Welch, E. (2004). Linking citizen satisfaction with e-government and trust in government. Journal of Public Administration Research and Theory. Vol 15 (3).

Hinnant, C. \& Welch, E. (2002). Internet Use, Transparency, and Interactivity, Effects on Trust in Government. Proceedings of the 36th Annual Hawaii International Conference on System Sciences

Hüller, T. (2007). Assessing EU strategies for publicity. Journal of European Public Policy, Vol.14(4), pp.563-581

Maastricht University. (2011). Maastricht University statistics. Retrieved June 5, 2011 from http://www.maastrichtuniversity.nl/web/Main/AboutUM/FactsFigures/MaastrichtUniversityStatistics.htm

Majone, G. (1998). Europe's 'Democratic Defecit': The Question of Standards. European Law Journal, Vol4(1), pp.5-28

Moravcsik, A. (2002) In Defence of the Democratic Deficit: Reassessing Legitimacy in the European Union. Journal of Common Market Studies Vol 40(4), pp.603-624

Obama, B. (2006). An Honest Government, A Hopeful Future, August 28, 2006 in Nairobi, Kenya. Retrieved June 3, 2011 from http://obamaspeeches.com/o88-An-Honest-Government-AHopeful-Future-Obama-Speech.htm

Stiglitz, J. (1999). On Liberty, the Right to Know, and Public Discourse: The Role of Transparency in Public Life. Oxford Amnesty Lecture, Oxford, UK

Sweeney, A. (2007). Electronic Government-Citizen Relationships: Exploring Citizen Perspectives. Journal of Information Technology \& Politics. Vol. 4(2). 